\title{
Explorando o Smartphone na Educação de Jovens e Adultos: Computação para a Autonomia Digital
}

\author{
Wictor Gomes \\ Departamento de Computação \\ UFRPE/Recife-PE \\ wictoracademico@gmail.com \\ Danielle Silva \\ Escola Estadual Lions de Parnamirim \\ Recife-PE \\ danielle_csilva@hotmail.com
}

\author{
Ulremberg Barbosa \\ Departamento de Computação \\ UFRPE/Recife-PE \\ ulremberg.silva@ufrpe.br \\ Rozelma França \\ Departamento de Educação \\ UFRPE / Recife - PE \\ rozelma.franca@ufrpe.br
}

A tecnologia digital avança de modo conspícuo e encontra-se ubiquamente no nosso cotidiano. O smartphone é um exemplo de dispositivo que apresenta uma grande importância para a massificação dos meios de comunicação, assim como do uso da Internet. Entretanto, há grupos de indivíduos que não possuem familiaridade para usufruir de maneira plena esse dispositivo. Exemplos de grupos que enfrentam esse empecilho são os idosos e pessoas de baixa renda. Sujeitos que apresentam ambas as condições ou predominantemente de baixa renda, estão no programa de Educação de Jovens e Adultos (EJA)[1][2]. São sujeitos que, seja por trabalho ou outros fatores, interromperam seus estudos e regressaram para o concluir. As dificuldades de uso dos dispositivos móveis por esses educandos os impedem de alcançar a sua autonomia digital, inclusive na atual situação de pandemia, e a sua formação.

$\mathrm{O}$ desenvolvimento de habilidades relacionadas à Cultura Digital já está previsto em propostas curriculares de Computação, como as da SBC [3] e do CIEB [4]. No entanto, elas não contemplam a EJA. Em outra direção, pesquisas têm buscado promover a Computação para esse público, tendo resultados promissores $[5,6,7]$, que fortalecem a necessidade desse tipo de investigação.

Visando compreender os sujeitos da pesquisa, estudantes e professores da EJA, um estudo etnográfico [8] foi realizado em uma escola estadual de Pernambuco. Como instrumentos de coleta foram adotados: observação de aulas remotas, questionário e entrevista semiestruturada. As observações se deram, principalmente, nos grupos de WhatsApp das turmas, empregados como principal canal de comunicação na escola durante a pandemia. Em relação ao questionário, foi criado pelo Google Forms para identificar o perfil socioeconômico e as vivências dos educandos com a tecnologia; bem como o perfil dos educadores. Posteriormente foram realizadas entrevistas semiestruturadas pelo Google Meet, visando compreender com mais profundidade os dados anteriormente coletados.

\footnotetext{
Fica permitido ao(s) autor(es) ou a terceiros a reprodução ou distribuição, em parte ou no todo, do material extraído dessa obra, de forma verbatim, adaptada ou remixada, bem como a criação ou produção a partir do conteúdo dessa obra, para fins não comerciais, desde que sejam atribuídos os devidos créditos à criação original, sob os termos da licença CC BY-NC 4.0.

EduComp'21, Abril 26-30, 2021, Jataí, Goiás, Brasil (On-line)

C2021 Copyright mantido pelo(s) autor(es). Direitos de publicação licenciados à Sociedade Brasileira de Computação (SBC).
}

Os dados coletados [9] revelam o interesse dos estudantes da EJA em desenvolver sua autonomia digital para atividades diversas do dia a dia. A partir disso, se propôs a "Desbravando o Smartphone". Tal ação busca explorar recursos básicos do smartphone, favorecendo o entendimento e realização de tarefas como: enviar mensagens, realizar ligações, tirar fotos e gravar áudio. Posteriormente, serão propostas, junto com os educadores, atividades gamificadas (e.g. Kahoot!) e interativas (e.g. criação de podcast), que articulem o letramento digital dos educandos aos conteúdos curriculares, favorecendo a interdisciplinaridade da Computação na escola. Como resultado desse projeto, almeja-se alcançar a autonomia desses educandos frente ao uso do smartphone, assim como o entendimento de como pilares do Pensamento Computacional podem ser desenvolvidos de forma tangencial às atividades propostas.

\section{AGRADECIMENTOS}

O presente trabalho foi realizado com apoio do Programa Institucional de Bolsa de Iniciação à Docência (PIBID) da Coordenação de Aperfeiçoamento de Pessoal de Nível Superior (CAPES) - Edital 02/2020.

\section{REFERÊNCIAS}

[1] Negreiros, F., da Costa Silva, C. F., de Sousa, Y. L. G., \& dos Santos, L. B. (2017). Análise psicossocial do fracasso escolar na Educação de Jovens e Adultos. Revista Psicologia em Pesquisa, 11(1).

[2] Pompermair, F. S., \& Moura, B. D. S. P. (2012). Destinos inconclusos: os jovens de uma escola de EJA no norte do estado do Espírito Santo. Revista Eletrônica Sala de Aula em Foco, 2(01), 87-100.

[3] SBC. Diretrizes para ensino de Computação na Educação Básica. Sociedade Brasileira de Computação. 2018. Disponível em: $<$ https://www.sbc.org.br/educacao/diretrizes-para-ensino-de-computacao-naeducacao-basica>. Acesso em 26 de fev. 2021.

[4] CIEB "Currículo de Referência em Tecnologia e Computação", Centro de Inovação para a Educação Brasileira, 2018. Disponível em: $<$ https://curriculo.cieb.net.br/>. Acesso em 26 de fev. 2021

[5] Bathke, J. D. S. Pensamento computacional e educação de jovens e adultos: na direção de um modelo socialmente consciente

[6] Bathke, J., \& Raabe, A. (2016, November). Pensamento computacional na educação de jovens e adultos: Lições aprendidas. In Anais dos Workshops do Congresso Brasileiro de Informática na Educação (Vol. 5, No. 1, p. 1087).

[7] Ortiz, J., \& Pereira, R. (2017, October). Pensamento Computacional na Educação de Jovens e Adultos: desafios e oportunidades. In Anais dos Workshops do Congresso Brasileiro de Informática na Educação (Vol. 6, No. 1, p. 1069).

[8] Creswell, J. W. (2014). Investigação Qualitativa e Projeto de Pesquisa-: Escolhendo entre Cinco Abordagens. Penso Editora.

[9] Universidade Federal Rural de Pernambuco (2021). Diagnose - PIBID/UFRPE Edital Capes 02/2020 Licenciatura em Computação - Escola Estadual Lions de 
EduComp'21, Abril 26-30, 2021, Jataí, Goiás, Brasil (On-line)

Gomes et al.

Parnamirim. Disponível em <https://www.flipsnack.com/pibidlions/copy-ofportf-lio-lions.html >. Acesso em 26 de fev. 2021. 